\title{
Obesity May Not Be a Risk of Non-Target Lesion Revascularization in the Elderly Patients A Retrospective Cohort Study
}

\author{
Kenichi Shibata, ${ }^{1,2}$ MSc, Masataka Kameshima, ${ }^{1}$ MSc, Hiroaki Fujiyama, ${ }^{1}$, Mariko Ehara, ${ }^{3}$ MD, \\ Yoriyasu Suzuki, ${ }^{3} \mathrm{MD}$ and Sumio Yamada, ${ }^{2} \mathrm{PhD}$
}

\begin{abstract}
Summary
Obesity is assumed to be one of the robust risk factors for coronary artery disease. However, the effects of obesity on the progression of atherosclerosis in patients in different age groups after percutaneous coronary intervention (PCI) remain unclear. This study aimed to examine the effect of obesity on prognosis in different age groups.

Consecutive patients who underwent urgent or elective PCI were surveyed for this study and were then divided into the elderly group and middle-aged group with a cut-off age of 70 years. All patients underwent coronary angiography or coronary computed tomography angiography 1 year after PCI to examine the progression of atherosclerosis. The primary endpoint was revascularization for a new lesion within 2 years after PCI. In addition, the main effects and correlations between obesity and age were examined. Multivariate logistic regression analysis was conducted to identify independent predictors of non-target lesion revascularization (non-TLR).

Of the 711 patients who met the criteria and were available for follow-up analysis, the incidence of nonTLR within 2 years was $97 / 711$ (13.6\%). The higher incidence of non-TLR in patients with obesity was observed only in the middle-aged group. Furthermore, in the multivariate analysis, obesity was independently associated with non-TLR only in the middle-aged group.

The findings of the present study would enable us to construct the hypothesis that obesity in elderly patients may not be an independent predictor of the incidence of non-TLR, indicating that the management to prevent non-TLR may vary depending on the age of the patient.
\end{abstract}

(Int Heart J 2021; 62: 726-733)

Key words: Coronary risk factors, Age, Percutaneous coronary intervention, Clinical outcomes, Japanese

$\mathrm{D}$ uring the past three decades, the prevalence of obesity among young Japanese people has gradually increased from $21.4 \%$ in $1981-1985$ to $36.5 \%$ in 2016 for men in the 50-59-year age bracket, ${ }^{1,2)}$ indicating that the effect of obesity on cardiovascular events may be one of the major risk factors. Patients with coronary artery disease (CAD) often have multiple coronary risk factors, including obesity, which can result in the development of other coronary risk factors, such as hypertension (HT), ${ }^{3,4)}$ dyslipidemia (DL), ${ }^{4}$ and diabetes mellitus (DM) ${ }^{4,5)}$ leading to the progression of atherosclerosis. ${ }^{6.7)}$ Adipose tissue dysfunction in persons with obesity has been reported as an underlying mechanism that promotes atherosclerosis-related diseases, such as CAD and cerebral infarction. ${ }^{8.9)}$ In addition, inflammation due to adipose tissue dysfunction causes atherosclerotic cardiovascular events through metabolic complications and adipocytokine dysregulation. ${ }^{10,11)}$ Although obesity offers a survival advantage in patients after percutaneous coronary inter- vention (PCI), ${ }^{12-14)}$ previous reports demonstrated a higher incidence of revascularization with the progression of coronary atherosclerosis in obese patients. ${ }^{15,16)}$ Therefore, the effects of obesity on the progression of atherosclerosis and the prognosis are contradictory.

Our speculation for the paradoxical effect of obesity is that obesity may have a different effect on the progression of atherosclerosis depending on age. In fact, in Japan, the impact of obesity on the development of acute myocardial infarction (AMI) has been reported only in the middle-aged patients. ${ }^{17}$ Contrarily, in the cohort study that examined the effect of obesity on the onset of ischemic heart disease in elderly males, the prognostic impact of obesity has been reported. ${ }^{18)}$ However, there are no reports on the effect of obesity on the progression of atherosclerosis following PCI. It is suggested that, in elderly patients with obesity, the altered cytokine and neuroendocrine profiles may play a role in the modulation of new lesion progression. ${ }^{19)}$ Thus, the effect of obesity on non-

From the ${ }^{1}$ Department of Cardiac Rehabilitation, Nagoya Heart Center, Nagoya, Japan, ${ }^{2}$ Department of Integrated Health Sciences, Nagoya University Graduate School of Medicine, Nagoya, Japan and ${ }^{3}$ Department of Cardiology, Nagoya Heart Center, Nagoya, Japan.

Address for correspondence: Sumio Yamada, PhD, Department of Integrated Health Sciences, Nagoya University Graduate School of Medicine, 1-1-20 Daiko-minami Higashi-ku, Nagoya 461-8673, Japan. E-mail: yamadas@met.nagoya-u.ac.jp

Received for publication October 26, 2020. Revised and accepted February 12, 2021.

Released in advance online on J-STAGE July 17, 2021.

doi: 10.1536/ihj.20-708

All rights reserved by the International Heart Journal Association. 
TLR in patients in different age groups following PCI remains unclear. This study, therefore, aimed to examine the effect of obesity on prognosis in different age groups following PCI.

\section{Methods}

Study design and participants: The present study was conducted as a single-center, retrospective, cohort study. Consecutive patients who underwent urgent or elective PCI at the Nagoya Heart Center from May 2013 to March 2016 were surveyed. Patients who met the following criteria were excluded: 1) chronic hemodialysis before PCI; 2) confirmation angiography not performed within 2 years after PCI; or 3) lack of clinical follow-up. Patients with target lesion revascularization (TLR) were included in the no repeated PCI group in this study. All patients underwent coronary angiography (CAG) or coronary computed tomography angiography (CCTA) 1 year after PCI to determine whether coronary artery stenosis had progressed. Moreover, the need for revascularization was determined. Progression of a new lesion was defined as the development of a coronary lesion that was insignificant at the initial PCI but required additional PCI due to ischemic symptoms and/or abnormal results of functional studies, including fractional flow reserve and treadmill testing. The patients' health status and the incidence of cardiovascular events and mortality were obtained from the medical records of the hospital. Only patients who visited our hospital for more than 2 years after PCI and whose medical records were available for follow-up were included in the analysis. The study protocol complied with the principles expressed in the Declaration of Helsinki. In addition, this study was approved by the Research Ethics Committee of the Nagoya University Graduate School of Medicine (Approval No.18-505).

Definitions: The deaths of the patients in this study were confirmed through the medical records from our hospital or information obtained from follow-up visits. The present study included information on the baseline characteristics of the patients and their cardiac history and risk factors at the initial PCI. Body mass index (BMI) was calculated at the initial PCI by dividing the patient's measured weight $(\mathrm{kg})$ by the square of the height $(\mathrm{m})$, and obesity was defined as a BMI $\geq 25 \mathrm{~kg} / \mathrm{m}^{2}$ based on the Japanese criterion for obesity. ${ }^{20)}$ To compare the effects by age, the elderly patients were defined as those aged $\geq 70$ years, whereas the middle-aged patients were defined as those aged $<70$ years. The clinical definition of DM included non-fasting glucose $\geq 200 \mathrm{mg} / \mathrm{dL}, \mathrm{HbAlc} \geq 6.5 \%$, oral hypoglycemic drug use, or insulin use. HT was defined as intake of antihypertensive drugs. DL was defined as triglyceride (TG) level $\geq 150 \mathrm{mg} / \mathrm{dL}$ and/or low-density lipoprotein-cholesterol (LDL-C) level $\geq 140 \mathrm{mg} / \mathrm{dL}$ and/or high-density lipoprotein-cholesterol (HDL-C) level $<40$ $\mathrm{mg} / \mathrm{dL}$ and/or receiving treatment with lipid-lowering agents.

The estimated glomerular filtration rate (eGFR) was calculated using the GFR equation for the Japanese population. ${ }^{21)}$ Chronic kidney disease (CKD) was defined as baseline $\mathrm{eGFR} \leq 60 \mathrm{~mL} \cdot$ minutes $^{-1} 1.73 \mathrm{~m}^{-2}$. ${ }^{22)} \mathrm{TLR}$ was defined as any repeat revascularization procedure (percutaneous or surgical) of the original target lesion site, including the stented area plus a margin, typically $5 \mathrm{~mm}$ proximal and distal to the stent. Multi-vessel disease (MVD) was defined as $\geq 2$-vessel disease with angiographic significant stenosis before the initial PCI.

Outcomes: Revascularization of an initially non-target lesion owing to its progression has emerged as a new therapeutic target of CAD in the previous reports. ${ }^{22,23)}$ Thus, in this study, we set revascularization for a non-target lesion as a new lesion for primary endpoint within 2 years following PCI.

Statistical analysis: The Wilk-Shapiro test was employed to assess the normality of data distributions. Continuous variables are expressed as mean \pm standard deviation or as median and interquartile range in the cases of non-normal distributions. Categorical data are expressed as percentages. The baseline characteristics were compared between the groups using unpaired $t$-test or the Mann-Whitney $U$ test for continuous variables and chi-squared test for categorical variables.

Multivariate logistic regression analysis was conducted to identify the independent prognostic factors for non-TLR. The main effects and correlations of obesity and age on non-TLR in the elderly and middle-aged patients were also analyzed. All the tests with two-sided $P$ values $<0.05$ were considered significant. All statistical analyses were conducted using IBM SPSS statistics v23 (SPSS, Inc., Chicago, IL) and EZR (Saitama Medical Center, Jichi Medical University, Saitama, Japan), ${ }^{24)}$ which is a graphical user interface for $\mathrm{R}$ ( $\mathrm{R}$ Foundation for Statistical Computing, Vienna, Austria).

\section{Results}

Of the 1,437 patients who underwent PCI during the study period, 711 met the criteria and were available for follow-up analysis (Figure 1). Among these patients, the prevalence of obesity was $38 \%$, and $43 \%$ of the patients were aged $\geq 70$ years. The prevalence of obesity was greater in the middle-aged group $(45.9 \%)$ than in the elderly group $(28.6 \%)$. Overall, DM and DL were more common in patients with obesity, and in terms of age, patients with obesity were significantly younger than those without. In a group comparison by age, the prevalence of both DM and DL were significantly higher in the middle-aged group but have no statistical difference in the elderly group (Table I).

In this study, the incidence rate of non-TLR within 2 years was $97 / 711(13.6 \%)$ patients. Of these, $74(10.4 \%)$ had undergone PCI at the 1-year follow-up period. The incidence rate of non-TLR in the middle-aged group was greater in patients with obesity, whereas reverse relationship was observed in elderly group (Figure 2).

Multivariate logistic regression analysis revealed that obesity was associated with non-TLR overall after adjustment for age $\geq 70$ years, sex, HT, DM, high LDL-C ( $\geq$ $140 \mathrm{mg} / \mathrm{dL}$ ), CKD, MVD, and prior PCI (Table II). Furthermore, a significant correlation between obesity and age on non-TLR was observed. The incidence rate distributions according to obesity and comorbidity are pre- 


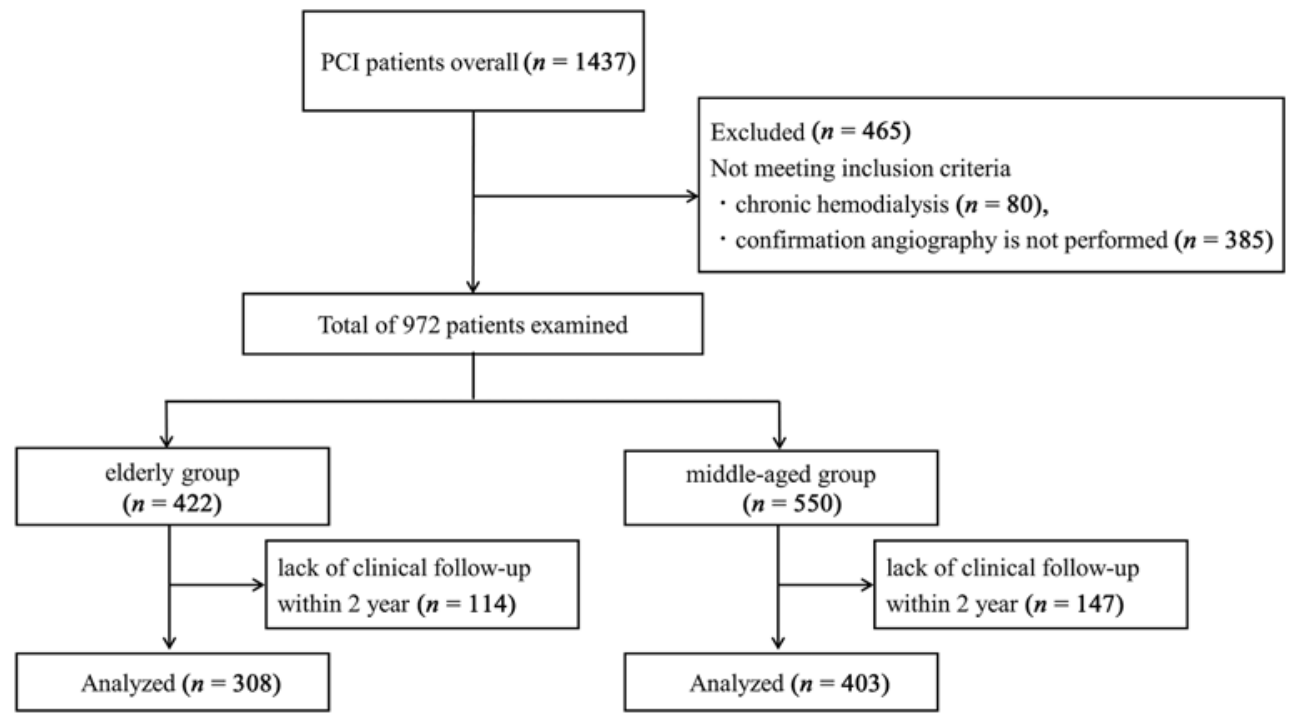

Figure 1. Study flow diagram. The cut-off age for the middle-aged and elderly groups is 70 years.

sented in each age group in Figure 3. In the elderly group, there was a significant correlation between obesity and HT on non-TLR. Contrarily, no correlation between obesity and comorbidity was observed in the middle-aged group (Table II). In the elderly group, HT and DM were significantly associated with non-TLR, whereas in the middle-aged group, obesity and MVD were significantly associated (Figure 4).

\section{Discussion}

The findings of this study indicated that obesity may not be an independent predictor of the incidence of nonTLR in the elderly patients. The difference in the predictors identified in this study, DM and HT for the elderly group and MVD and obesity for the middle-aged group, suggests that the post-PCI management strategies for preventing non-TLR may vary depending on patient characteristics and age. Based on the findings of this study, we propose that obesity in the elderly patients may not be uniformly recognized as a risk factor for non-TLR but should be recognized as a risk in connection with consideration of other comorbidities.

In the present study, the incidence rate of non-TLR was $74(10.4 \%)$ at 1 year and $97(13.6 \%)$ at 2 years in patients who underwent primary PCI; the incidence rate at 2 years was not different between the elderly and the middle-aged groups (13.9\% versus $13.3 \%$, respectively). Glaser, et al. reported that approximately $6 \%$ of PCI patients required clinically driven PCI for non-target lesion by 1 year. ${ }^{25}$ The studies in the Japanese population that examined the incidence rate of non-TLR showed rates of approximately $9.5 \%-16 \%$ within 1 year ${ }^{22,26,27)}$ and $21 \%$ within 2 years. ${ }^{26)}$ Another factor considered in the generalization of the results is lipid-lowering medications. The importance of the LDL-C-lowering therapy has been emphasized, and aggressive lipid management has recently been recommended. ${ }^{28,29)}$ According to the reports of the prescription rate for statins in 2010 in Japan, only $24 \%$ of the patients had achieved the level of LDL-C $<100 \mathrm{mg} /$ $\mathrm{dL}$, which is sufficient for secondary prevention as recommended by the guidelines at the time. ${ }^{29,30)}$ In our study, in the PCI patients from 2013 to 2016, the achievement rate of LDL-C $<100 \mathrm{mg} / \mathrm{dL}$ was as high as $67 \%$, indicating that a more aggressive lipid management had been performed. This achievement rate may have led to the low incidence rate of new lesion PCI. The incidence rate of non-TLR and higher achievement rate of LDL-C in our study patients suggest that the findings of this study may provide an acceptable basis for constructing a hypothesis.

In this study, obesity and MVD were independently associated with non-TLR in the middle-aged patients, a finding that is in agreement with the previous reports. ${ }^{15,22,25)}$ In particular, obesity was independently associated with non-TLR in the middle-aged patients but not in the elderly patients. A meta-analysis including aged patients reported that obesity was an independent predictor of repeat revascularization. ${ }^{15)}$ However, the study did not analyze a group difference depending on age. With regard to the issues of the effects of age on obesity, a recent study demonstrated that obesity was an independent risk factor for AMI in young and middle-aged males but not in older (60-80 years) or very old males (> 80 years) ${ }^{17)}$ Another study showed that the association between obesity and a cluster of cardiometabolic risk factors was stronger in young than in elderly males. ${ }^{31}$ The findings of these studies indicate that the progression of atherosclerosis caused by adipose tissue dysfunction due to obesity may particularly be pronounced in middle-aged patients. However, the underlying mechanisms for the age-related variability of the effects of obesity on new lesion progression have remained unclear.

In agreement with the report of Shiraishi, et al., ${ }^{17)}$ obesity was not found to be a predictor for non-TLR in the elderly group. One possible explanation for this variability is that the altered cytokine and neuroendocrine pro- 
Table I. Patient Characteristics

\begin{tabular}{|c|c|c|c|c|c|c|c|c|c|}
\hline & \multicolumn{3}{|c|}{ Overall, $(n=711)$} & \multicolumn{3}{|c|}{ Elderly, $(n=308)$} & \multicolumn{3}{|c|}{ Middle-aged, $(n=403)$} \\
\hline & $\begin{array}{l}\text { Obesity } \\
n=273\end{array}$ & $\begin{array}{c}\text { Non-obesity } \\
n=438\end{array}$ & $P$ & $\begin{array}{c}\text { Obesity } \\
n=88\end{array}$ & $\begin{array}{c}\text { Non-obesity } \\
n=220\end{array}$ & $P$ & $\begin{array}{l}\text { Obesity } \\
n=185\end{array}$ & $\begin{array}{l}\text { Non-obesity } \\
\quad n=218\end{array}$ & $P$ \\
\hline Age (years) & $63.3 \pm 10.6$ & $68.5 \pm 9.3$ & $<0.001$ & $75.2 \pm 4.0$ & $75.7 \pm 4.5$ & 0.307 & $57.7 \pm 7.6$ & $61.1 \pm 6.8$ & $<0.001$ \\
\hline Men, $n(\%)$ & $238(87.2 \%)$ & $331(75.6 \%)$ & $<0.001$ & $68(77.3 \%)$ & $153(69.5 \%)$ & 0.208 & $170(91.9 \%)$ & $178(81.7 \%)$ & 0.003 \\
\hline BMI $\left(\mathrm{kg} / \mathrm{m}^{2}\right)$ & $27.5 \pm 2.5$ & $22.2 \pm 2.0$ & $<0.001$ & $26.9 \pm 1.8$ & $22.2 \pm 2.1$ & $<0.001$ & $27.8 \pm 2.7$ & $22.3 \pm 1.8$ & $<0.001$ \\
\hline ACS, $n(\%)$ & $45(16.5 \%)$ & $58(13.2 \%)$ & 0.273 & $8(9.1 \%)$ & $26(11.8 \%)$ & 0.552 & $37(20.0 \%)$ & $32(14.7 \%)$ & 0.185 \\
\hline Prior PCI, $n(\%)$ & $68(24.9 \%)$ & $111(25.3 \%)$ & 0.929 & $23(26.1 \%)$ & $60(27.3 \%)$ & 0.888 & $45(24.3 \%)$ & $51(23.4 \%)$ & 0.907 \\
\hline $\mathrm{MVD}, n(\%)$ & $157(57.5 \%)$ & $227(51.8 \%)$ & 0.142 & $53(60.2 \%)$ & $126(57.3 \%)$ & 0.702 & $104(56.2 \%)$ & $101(46.3 \%)$ & 0.057 \\
\hline Smoking, $n(\%)$ & $72(27.4 \%)$ & $107(25.0 \%)$ & 0.531 & $10(11.9 \%)$ & $38(17.8 \%)$ & 0.293 & $62(34.6 \%)$ & $69(32.2 \%)$ & 0.668 \\
\hline \multicolumn{10}{|l|}{ Comorbidity } \\
\hline $\begin{array}{l}\text { Diabetes mellitus, } \\
n(\%)\end{array}$ & $111(40.8 \%)$ & $134(30.9 \%)$ & 0.009 & $37(42.5 \%)$ & $83(38.1 \%)$ & 0.517 & $74(40.0 \%)$ & $51(23.7 \%)$ & 0.001 \\
\hline $\begin{array}{l}\text { Hypertension, } \\
n(\%)\end{array}$ & $178(65.2 \%)$ & $262(59.8 \%)$ & 0.154 & $66(75.0 \%)$ & $142(64.5 \%)$ & 0.082 & $112(60.5 \%)$ & $120(55.0 \%)$ & 0.312 \\
\hline $\begin{array}{l}\text { Dyslipidemia, } \\
n(\%)\end{array}$ & $207(75.8 \%)$ & $286(65.3 \%)$ & 0.003 & $64(72.7 \%)$ & $148(67.3 \%)$ & 0.414 & $143(77.3 \%)$ & $138(63.3 \%)$ & 0.002 \\
\hline $\begin{array}{l}\text { Chronic kidney } \\
\text { disease, } n(\%)\end{array}$ & $83(30.4 \%)$ & $147(33.6 \%)$ & 0.41 & $45(51.1 \%)$ & $104(47.3 \%)$ & 0.614 & $38(20.5 \%)$ & $43(19.7 \%)$ & 0.901 \\
\hline \multicolumn{10}{|c|}{ BMI, laboratory data, and blood pressure at follow-up } \\
\hline $\operatorname{BMI}\left(\mathrm{kg} / \mathrm{m}^{2}\right)$ & $27.2 \pm 2.8$ & $22.2 \pm 2.1$ & $<0.001$ & $26.4 \pm 2.3$ & $22.1 \pm 2.2$ & $<0.001$ & $27.6 \pm 3.0$ & $22.4 \pm 2.1$ & $<0.001$ \\
\hline LDL-C (mg/dL) & $93.9 \pm 27.1$ & $91.8 \pm 27.0$ & 0.317 & $92.8 \pm 24.3$ & $90.1 \pm 25.6$ & 0.396 & $94.4 \pm 28.4$ & $93.4 \pm 28.4$ & 0.738 \\
\hline LDL-C $<70, n(\%)$ & $51(19.1 \%)$ & $98(22.5 \%)$ & 0.297 & $14(16.1 \%)$ & $52(23.9 \%)$ & 0.166 & $37(20.6 \%)$ & $46(21.1 \%)$ & 0.902 \\
\hline $\begin{array}{l}\text { LDL-C }<100, \\
n(\%)\end{array}$ & $177(64.8 \%)$ & $299(68.3 \%)$ & 0.368 & $60(68.2 \%)$ & $154(70.0 \%)$ & 0.785 & $117(63.2 \%)$ & $145(66.5 \%)$ & 0.53 \\
\hline HDL-C (mg/dL) & $45.8 \pm 10.7$ & $52.7 \pm 14.6$ & $<0.001$ & $47.0 \pm 9.7$ & $52.4 \pm 14.5$ & 0.002 & $45.2 \pm 11.2$ & $53.1 \pm 14.7$ & $<0.001$ \\
\hline $\begin{array}{l}\text { Non HDL-C } \\
(\mathrm{mg} / \mathrm{dL})\end{array}$ & $\begin{array}{c}121.9 \pm \\
31.8\end{array}$ & $118.9 \pm 29.3$ & 0.194 & $\begin{array}{c}120.8 \pm \\
27.2\end{array}$ & $117.7 \pm 27.3$ & 0.376 & $\begin{array}{c}122.5 \pm \\
33.8\end{array}$ & $\begin{array}{c}120.1 \pm \\
31.2\end{array}$ & 0.461 \\
\hline $\mathrm{TG}(\mathrm{mg} / \mathrm{dL})$ & $\begin{array}{l}177.3 \pm \\
151.3\end{array}$ & $149.6 \pm 89.1$ & 0.002 & $\begin{array}{l}155.1 \pm \\
84.2\end{array}$ & $140.4 \pm 73.3$ & 0.131 & $\begin{array}{c}188.0 \pm \\
173.9\end{array}$ & $\begin{array}{c}158.8 \pm \\
101.8\end{array}$ & 0.105 \\
\hline HbAlc (\%) & $6.3 \pm 0.9$ & $6.1 \pm 0.8$ & 0.001 & $6.3 \pm 0.8$ & $6.3 \pm 0.9$ & 0.581 & $6.6 \pm 1.5$ & $6.1 \pm 0.9$ & $<0.001$ \\
\hline $\begin{array}{l}\text { eGFR }(\mathrm{mL} / \\
\left.\text { minute/1.73 } \mathrm{m}^{2}\right)\end{array}$ & $63.9 \pm 14.0$ & $61.4 \pm 14.0$ & 0.053 & $57.8 \pm 14.2$ & $59.6 \pm 13.6$ & 0.279 & $68.0 \pm 12.5$ & $66.2 \pm 13.4$ & 0.235 \\
\hline $\mathrm{SBP}(\mathrm{mmHg})$ & $\begin{array}{c}133.1 \pm \\
22.0\end{array}$ & $130.7 \pm 23.7$ & 0.262 & $\begin{array}{c}137.4 \pm \\
23.7\end{array}$ & $131.7 \pm 25.9$ & 0.14 & $\begin{array}{l}130.9 \pm \\
20.8\end{array}$ & $\begin{array}{l}129.5 \pm \\
21.3\end{array}$ & 0.605 \\
\hline $\mathrm{DBP}(\mathrm{mmHg})$ & $72.6 \pm 12.3$ & $67.3 \pm 12.2$ & $<0.001$ & $68.5 \pm 12.9$ & $64.7 \pm 12.6$ & 0.05 & $74.7 \pm 11.5$ & $70.1 \pm 11.1$ & 0.002 \\
\hline \multicolumn{10}{|c|}{ Medications at follow-up $(n=656)$} \\
\hline Aspirin, $n(\%)$ & $253(100 \%)$ & $403(100 \%)$ & 1.0 & $80(98.8 \%)$ & $204(100 \%)$ & 0.284 & $173(100 \%)$ & $199(99.0 \%)$ & 0.501 \\
\hline $\begin{array}{l}\text { ACE-Is or ARBs, } \\
n(\%)\end{array}$ & $157(62.1 \%)$ & $210(51.9 \%)$ & 0.012 & $50(61.7 \%)$ & $105(51.5 \%)$ & 0.147 & $107(62.2 \%)$ & $105(52.2 \%)$ & 0.059 \\
\hline $\begin{array}{l}\text { Calcium channel } \\
\text { blockers, } n(\%)\end{array}$ & $101(39.9 \%)$ & $142(35.1 \%)$ & 0.214 & $31(38.3 \%)$ & $74(36.3 \%)$ & 0.786 & $70(40.7 \%)$ & $68(33.8 \%)$ & 0.197 \\
\hline Statins, $n(\%)$ & $211(83.4 \%)$ & $321(79.3 \%)$ & 0.222 & $61(75.3 \%)$ & $153(75.0 \%)$ & 1.0 & $150(87.2 \%)$ & $168(83.6 \%)$ & 0.38 \\
\hline $\begin{array}{l}\text { Oral hypoglycemic } \\
\text { drugs, } n(\%)\end{array}$ & $90(35.6 \%)$ & $87(21.5 \%)$ & $<0.001$ & $30(37.0 \%)$ & $54(26.5 \%)$ & 0.085 & $60(34.9 \%)$ & $33(16.4 \%)$ & $<0.001$ \\
\hline Insulin, $n(\%)$ & $7(2.8 \%)$ & $11(2.7 \%)$ & 1.0 & $2(2.5 \%)$ & $6(2.9 \%)$ & 1.0 & $5(2.9 \%)$ & $5(2.5 \%)$ & 1.0 \\
\hline
\end{tabular}

Values are numbers $(\%)$ or mean \pm SD. BMI indicates body mass index; PCI, percutaneous coronary intervention; MVD, multi-vessel disease; ACS, acute coronary syndrome; LDL-C, low-density lipoprotein cholesterol; HDL-C, high-density lipoprotein cholesterol; TG, triglyceride; eGFR, estimated glomerular filtration rate; SBP, systolic blood pressure; DBP, diastolic blood pressure; ACE-I, angiotensin-converting enzyme inhibitor; and ARB, angiotensin II receptor blocker.

files of the elderly patients with obesity may play a key role in the modulation of new lesion progression. ${ }^{19)}$ Increased TNF- $\alpha$ and CRP levels at pre-PCI have been reported to predict major adverse cardiac events, including revascularization. ${ }^{32)}$ However, the effect of TNF- $\alpha$ will be possibly modulated by soluble $\mathrm{TNF}-\alpha$ receptors from the adipose tissue, which results in the neutralization of the biologic effects of TNF- $\alpha .^{33)}$ These studies and the findings of this study indicate that the metabolic activity of the adipose tissues may act differently depending on age, more aggressively in the middle-aged patients and less aggressively in the elderly patients, resulting in the cardio- vascular protective effect in the elderly patients with obesity.

Another issue related to the cardiovascular protective effect of the adipose tissue is its antioxidative effect. Oxidative stress increases with age, causing atherosclerosis progression. ${ }^{34)}$ However, the adipose tissue may counteract oxidative stress via endothelial function by producing adiponectin. ${ }^{35)}$ It has been reported that the concentrations of adiponectin were positively correlated with age. ${ }^{36,37)}$ Along with the antiinflammatory effect, the antioxidative effect of the adipose tissue may be modulated in the elderly patients by the effects of adiponectin. Furthermore, da Cruz, 




Figure 2. Incidence rate according to obesity in each age group.

Table II. Logistic Regression Analysis for the Association Between Obesity, Age, and Comorbidity

\begin{tabular}{|c|c|c|c|c|}
\hline & \multicolumn{3}{|c|}{ Obesity } & \multirow[t]{2}{*}{$P$ for interaction } \\
\hline & OR & $95 \%$ CI & $P$ value & \\
\hline Overall* & 1.87 & $1.02-3.43$ & 0.043 & \\
\hline Age group $* *$ & & & & 0.04 \\
\hline Elderly ( $\geq 70$ years) & 0.61 & $0.28-1.33$ & 0.21 & \\
\hline Middle-aged ( $<70$ years) & 1.97 & $1.04-3.76$ & 0.038 & \\
\hline \multicolumn{5}{|l|}{ Comorbidity } \\
\hline \multicolumn{5}{|l|}{ Elderly } \\
\hline HT $\times$ obesity & & & & 0.037 \\
\hline $\mathrm{HT}(+)(n=208)$ & 0.54 & $0.23-1.25$ & 0.15 & \\
\hline HT $(-)(n=100)$ & 3.95 & $0.74-21.10$ & 0.11 & \\
\hline $\mathrm{DM} \times$ obesity & & & & 0.29 \\
\hline $\mathrm{DM}(+)(n=120)$ & 1.06 & $0.39-2.86$ & 0.91 & \\
\hline $\mathrm{DM}(-)(n=188)$ & 0.44 & $0.12-1.58$ & 0.21 & \\
\hline DL $\times$ obesity & & & & 0.96 \\
\hline $\operatorname{DL}(+)(n=212)$ & 0.81 & $0.35-1.84$ & 0.61 & \\
\hline $\operatorname{DL}(-)(n=96)$ & 0.84 & $0.16-4.37$ & 0.84 & \\
\hline \multicolumn{5}{|l|}{ Middle-aged } \\
\hline HT $\times$ obesity & & & & 0.7 \\
\hline $\mathrm{HT}(+)(n=232)$ & 2.01 & $0.96-4.22$ & 0.064 & \\
\hline $\mathrm{HT}(-)(n=171)$ & 2.56 & $0.95-6.86$ & 0.062 & \\
\hline $\mathrm{DM} \times$ obesity & & & & 0.64 \\
\hline $\mathrm{DM}(+)(n=125)$ & 1.75 & $0.62-4.91$ & 0.29 & \\
\hline $\mathrm{DM}(-)(n=278)$ & 2.35 & $1.13-4.89$ & 0.022 & \\
\hline DL $\times$ obesity & & & & 0.88 \\
\hline $\operatorname{DL}(+)(n=281)$ & 2.22 & $1.07-4.63$ & 0.032 & \\
\hline $\operatorname{DL}(-)(n=122)$ & 2.45 & $0.87-6.93$ & 0.09 & \\
\hline
\end{tabular}

OR indicates odds ratio; CI, confidence interval; HT, Hypertension; DM, Diabetes mellitus; DL, Dyslipidemia; CKD, Chronic kidney disease; MVD, multi-vessel disease; PCI, percutaneous coronary intervention; and LDL-C, low-density lipoprotein cholesterol. *Adjusted for age $\geq 70$ years, sex, HT, DM, CKD, High LDL-C ( $\geq 140 \mathrm{mg} / \mathrm{dL})$ at baseline, MVD, and prior PCI. **Adjusted for age, sex, HT, DM, and MVD in each age group.

et $a l .^{38)}$ reported that lower plasma total antioxidant capacity had a significant correlation with the presence of HT and DM in community-dwelling elderly persons with chronic diseases. Interestingly, both HT and DM were also found to be independent risk factors in the elderly patients in this study. Another study reported that a higher plasma endothelin-1 level in HT and DM patients was independently associated with a lower plasma antioxidant status. ${ }^{39)}$ In the present study, approximately $70 \%$ of the elderly patients had HT and $40 \%$ had DM; these diseases were more prevalent in the elderly group than in the middle-aged group, suggesting higher oxidative stress in the elderly patients. Although the findings of this study (Figure 3 ) imply a possibility of antioxidative capacity of the adipose tissues in the elderly group, the underlying mechanisms remain unclear. Based on the above, we pro- 
elderly group

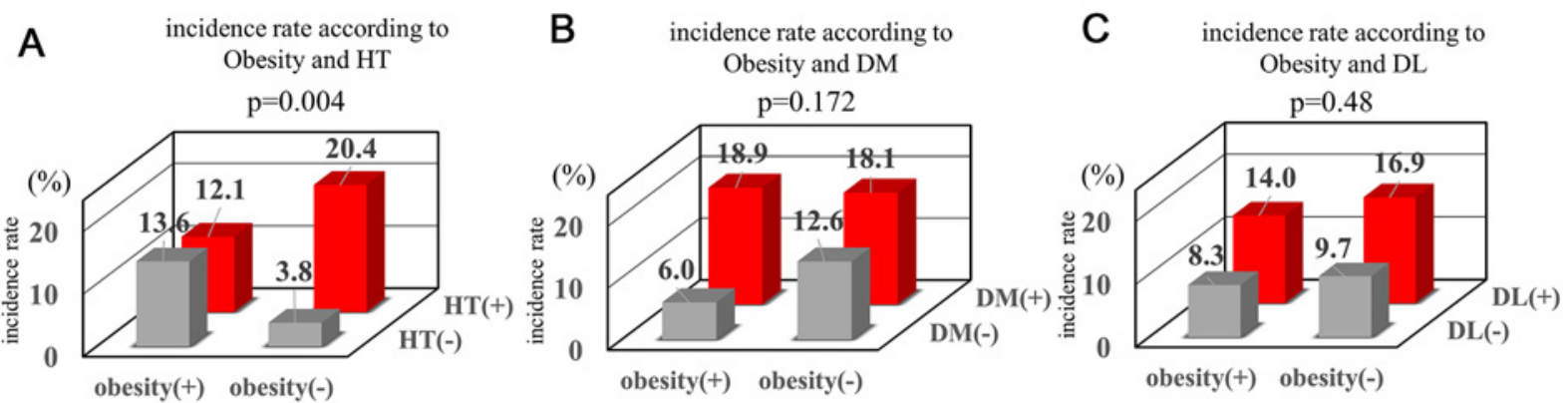

middle-aged group
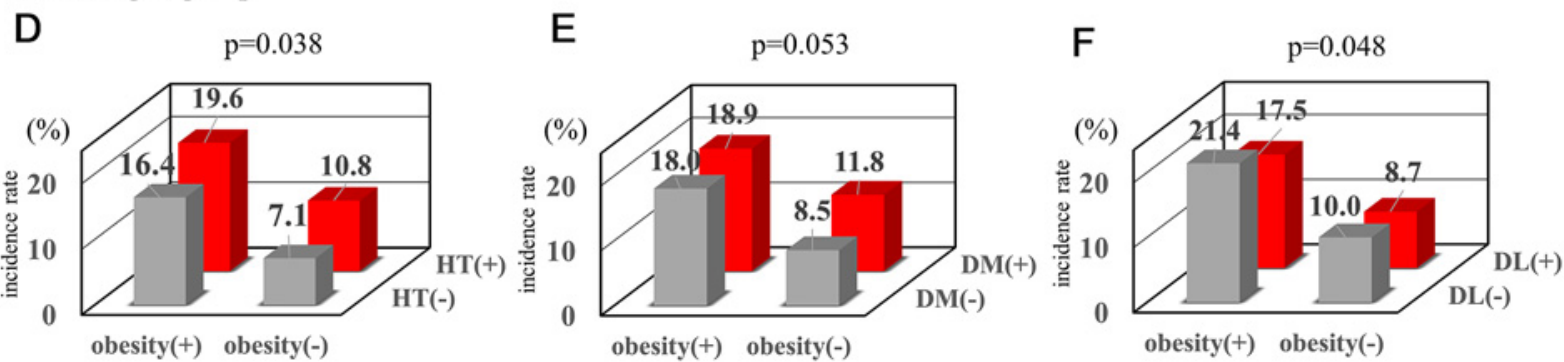

Figure 3. Incidence rate distribution according to obesity and comorbidity in each age group. The incidence rate in the elderly group is expressed according to obesity and HT (A), obesity and DM (B), and obesity and HL (C). The incidence rate in the middle-aged group is expressed according to obesity and HT (D), obesity and DM (E), and obesity and DL (F).

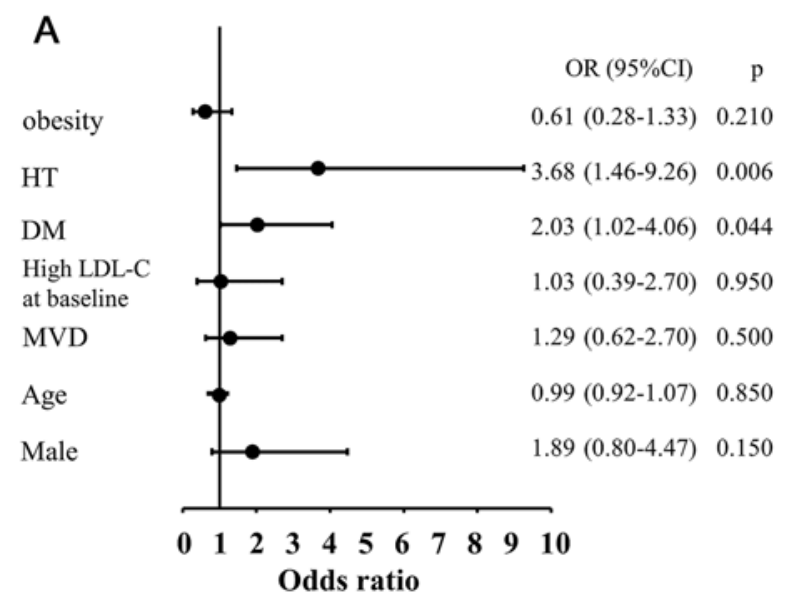

elderly group

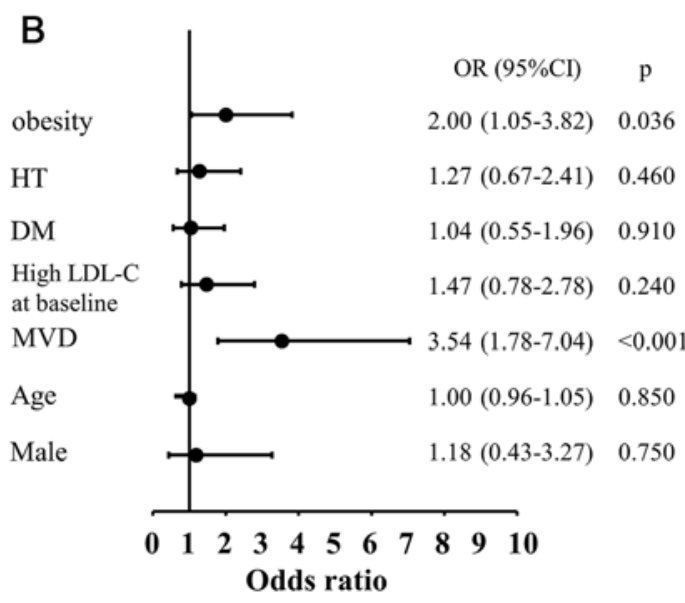

middle-aged group

Figure 4. Independent predictors of non-TLR in each group, elderly group (A) and middle-aged group (B). HT indicates hypertension; DM, diabetes mellitus; MVD, multi-vessel disease; and CI, confidence interval. High LDL-C was defined as LDL-C level $\geq 140$ $\mathrm{mg} / \mathrm{dL}$.

pose that obesity in the elderly patients after PCI should be managed taking into consideration other comorbidities.

This study has several limitations that need to be recognized. First, this is a single-center and retrospective study, and the findings of this study should be prospectively confirmed using large samples in multiple facilities before they can be generalized. Second, BMI was measured at baseline; therefore, the effect of the changes in BMI on atherosclerotic progression remains unclear. In addition, we could not exclude the possibility of the influ- ence of weight-lowering diseases, such as malignancy or inflammatory disease. Therefore, the changes in BMI after PCI and the diseases that cause weight reduction need to be investigated in the future. Third, the BMI in this study is likely to reflect muscle mass. Other measures of obesity, such as waist circumference and the waist-to-hip ratio, might better reflect body fat content and distribution than the BMI itself. Nevertheless, the findings of this retrospective study hypothesized that unnecessary weight reduction in elderly patients after PCI should be avoided. 
Further study is needed to determine the ideal body weight based on age distribution to prevent the progression of atherosclerosis.

\section{Conclusion}

In conclusion, the findings of the present study would enable us to construct the hypothesis that obesity in elderly patients may not be an independent predictor of the incidence of non-TLR, suggesting that the management strategies for preventing non-TLR may vary depending on age. Obesity in elderly patients may be recognized as a risk factor for non-TLR taking into consideration other comorbidities.

\section{Disclosure}

Conflicts of interest: The authors declare that there is no conflict of interest.

\section{References}

1. Yoshiike N, Seino F, Tajima S, et al. Twenty-year changes in the prevalence of overweight in Japanese adults: the national nutrition survey 1976-95. Obes Rev 2002; 3: 183-90.

2. The national health and nutrition survey in Japan (in Japanese). 2016. Available at: http://www.mhlw.go.jp/bunya/kenkou/eiyou/d 1/h28-houkoku.pdf. Accessed March 23, 2020.

3. Esler M, Straznicky N, Eikelis N, Masuo K, Lambert G, Lambert E. Mechanisms of sympathetic activation in obesity-related hypertension. Hypertension 2006; 48: 787-96.

4. Ishikawa-Takata K, Ohta T, Moritaki K, Gotou T, Inoue S. Obesity, weight change and risks for hypertension, diabetes and hypercholesterolemia in Japanese men. Eur J Clin Nutr 2002; 56 : 601-7.

5. Collaboration APCSAsia Pacific Cohort Studies Collaboration, Ni Mhurchu C, Parag V, et al. Body mass index and risk of diabetes mellitus in the Asia-Pacific region. Asia Pac. J. Clin. Nutr. 2006; 15: 127-33.

6. Rana JS, Mittleman MA, Ho KK, Cutlip DE. Obesity and clinical restenosis after coronary stent placement. Am Heart J 2005; 150: 821-6.

7. Doi Y, Ninomiya T, Hata J, et al. Proposed criteria for metabolic syndrome in Japanese based on prospective evidence: the Hisayama study. Stroke 2009; 40: 1187-94.

8. Matsuzawa Y, Funahashi T, Kihara S, Shimomura I. Adiponectin and metabolic syndrome. Arterioscler Thromb Vasc Biol 2004; 24: 29-33.

9. Sato F, Maeda N, Yamada T, et al. Association of epicardial, visceral, and subcutaneous fat with cardiometabolic diseases. Circ J 2018; 82: 502-8.

10. Elagizi A, Kachur S, Lavie CJ, et al. An overview and update on obesity and the obesity paradox in cardiovascular diseases. Prog Cardiovasc Dis 2018; 61: 142-50.

11. Nakayama Y, Fujiu K. Effects of adipocyte expansion on cardiovascular system and ongoing debate over obesity paradox. Int Heart J 2019; 60: 499-502.

12. Romero-Corral A, Montori VM, Somers VK, et al. Association of bodyweight with total mortality and with cardiovascular events in coronary artery disease: a systematic review of cohort studies. Lancet 2006; 368: 666-78.

13. Park DW, Kim YH, Yun SC, et al. Association of body mass index with major cardiovascular events and with mortality after percutaneous coronary intervention. Circ Cardiovasc Interv 2013; 6: 146-53
14. Gruberg L, Weissman NJ, Waksman R, et al. The impact of obesity on the short-term and long-term outcomes after percutaneous coronary intervention: the obesity paradox? J Am Coll Cardiol 2002; 39: 578-84

15. Wang ZJ, Gao F, Cheng WJ, Yang Q, Zhou YJ. Body mass index and repeat revascularization after percutaneous coronary intervention: a meta-analysis. Can J Cardiol 2015; 31: 800-8.

16. Wang ZJ, Zhou YJ, Zhao YX, et al. Effect of obesity on repeat revascularization in patients undergoing percutaneous coronary intervention with drug-eluting stents. Obesity (Silver Spring) 2012; 20: 141-6.

17. Shiraishi J, Kohno Y, Sawada T, et al. Relation of obesity to acute myocardial infarction in Japanese patients. Circ J 2006; 70: $1525-30$

18. Dey DK, Lissner L. Obesity in 70-year-old subjects as a risk factor for 15-year coronary heart disease incidence. Obes Res 2003; 11: 817-27.

19. Dorner TE, Rieder A. Obesity paradox in elderly patients with cardiovascular diseases. Int J Cardiol 2012; 155: 56-65.

20. Matsuzawa Y, Inoue S, Ikeda Y, et al. Atarashii himan no hantei to himanshou no shindan kijun (New diagnostic criteria for obesity and obesity disease) [in Japanese]. J Japan Soc Study Obes 2000; 6: 18-28.

21. Matsuo S, Imai E, Horio M, et al. Revised equations for estimated GFR from serum creatinine in Japan. Am J Kidney Dis 2009; 53: 982-92.

22. Kaneko H, Yajima J, Oikawa Y, et al. Long-term incidence and prognostic factors of the progression of new coronary lesions in Japanese coronary artery disease patients after percutaneous coronary intervention. Heart Vessels 2014; 29: 437-42.

23. Fukuda Y, Miura S, Tsuchiya Y, et al. Lower frequency of nontarget lesion intervention in post-successful percutaneous coronary intervention patients with an LDL to HDL cholesterol ratio below 1.5. Int J Cardiol 2011; 149: 120-2.

24. Kanda Y. Investigation of the freely available easy-to-use software 'EZR' for medical statistics. Bone Marrow Transplant 2013; 48: 452-8.

25. Glaser R, Selzer F, Faxon DP, et al. Clinical progression of incidental, asymptomatic lesions discovered during culprit vessel coronary intervention. Circulation 2005; 111: 143-9.

26. Kimura $T$, Morimoto $T$, Nakagawa $\mathrm{Y}$, et al. Very late stent thrombosis and late target lesion revascularization after sirolimus-eluting stent implantation: five-year outcome of the $\mathrm{j}$ cypher registry. Circulation 2012; 125: 584-91.

27. Yamaji K, Shiomi H, Morimoto T, et al. Influence of sex on long-term outcomes after implantation of bare-metal stent: a multicenter report from the Coronary Revascularization Demonstrating Outcome Study-Kyoto (CREDO-Kyoto) Registry Cohort-1. Circulation 2015; 132: 2323-33.

28. Catapano AL, Graham I, De Backer G, et al. 2016 ESC/EAS Guidelines for the management of dyslipidaemias. Eur Heart $\mathrm{J}$ 2016; 37: 2999-3058.

29. Kinoshita M, Yokote K, Arai H, et al. Japan Atherosclerosis Society (JAS) guidelines for prevention of atherosclerotic cardiovascular diseases 2017. J Atheroscler Thromb 2018; 25: 846984.

30. Teramoto T, Kashiwagi A, Ishibashi S, Daida H, Japan Lipid Guideline Achievement Program Investigators. Cross-sectional survey to assess the status of lipid management in high-risk patients with dyslipidemia: clinical impact of combination therapy with ezetimibe. Curr Ther Res Clin Exp 2012; 73: 1-15.

31. Wakabayashi I. Age-dependent influence of gender on the association between obesity and a cluster of cardiometabolic risk factors. Gend Med 2012; 9: 267-77.

32. Kubica J, Kozinski M, Krzewina-Kowalska A, et al. Combined periprocedural evaluation of CRP and TNF-alpha enhances the prediction of clinical restenosis and major adverse cardiac events in patients undergoing percutaneous coronary interventions. Int J Mol Med 2005; 16: 173-80.

33. Mohamed-Ali V, Goodrick S, Bulmer K, Holly JMP, Yudkin JS, 
Coppack SW. Production of soluble tumor necrosis factor receptors by human subcutaneous adipose tissue in vivo. Am J Physiol 1999; 277: E971-5.

34. Golden TR, Hinerfeld DA, Melov S. Oxidative stress and aging: beyond correlation. Aging Cell 2002; 1: 117-23.

35. Xia N, Li H. The role of perivascular adipose tissue in obesityinduced vascular dysfunction. Br J Pharmacol 2017; 174: 342542.

36. Cnop M, Havel PJ, Utzschneider KM, et al. Relationship of adiponectin to body fat distribution, insulin sensitivity and plasma lipoproteins: evidence for independent roles of age and sex.
Diabetologia 2003; 46: 459-69.

37. Isobe T, Saitoh S, Takagi S, et al. Influence of gender, age and renal function on plasma adiponectin level: the Tanno and Sobetsu study. Eur J Endocrinol 2005; 153: 91-8.

38. Da Cruz AC, Petronilho F, Heluany CCV, et al. Oxidative stress and aging: correlation with clinical parameters. Aging Clin Exp Res 2014; 26: 7-12.

39. Skalska AB, Pietrzycka A, Stepniewski M. Correlation of endothelin 1 plasma levels with plasma antioxidant capacity in elderly patients treated for hypertension. Clin Biochem 2009; 42: 358-64. 